This item was submitted to Loughborough's Research Repository by the author.

Items in Figshare are protected by copyright, with all rights reserved, unless otherwise indicated.

\title{
Development of a MSW classification system for the evaluation of
} mechanical properties

PLEASE CITE THE PUBLISHED VERSION

PUBLISHER

(C) Elsevier Ltd

VERSION

AM (Accepted Manuscript)

LICENCE

CC BY-NC-ND 4.0

\section{REPOSITORY RECORD}

Dixon, Neil, and Ulrich Langer. 2019. "Development of a MSW Classification System for the Evaluation of Mechanical Properties". figshare. https://hdl.handle.net/2134/4375. 
This item was submitted to Loughborough's Institutional Repository (https://dspace.lboro.ac.uk/) by the author and is made available under the following Creative Commons Licence conditions.

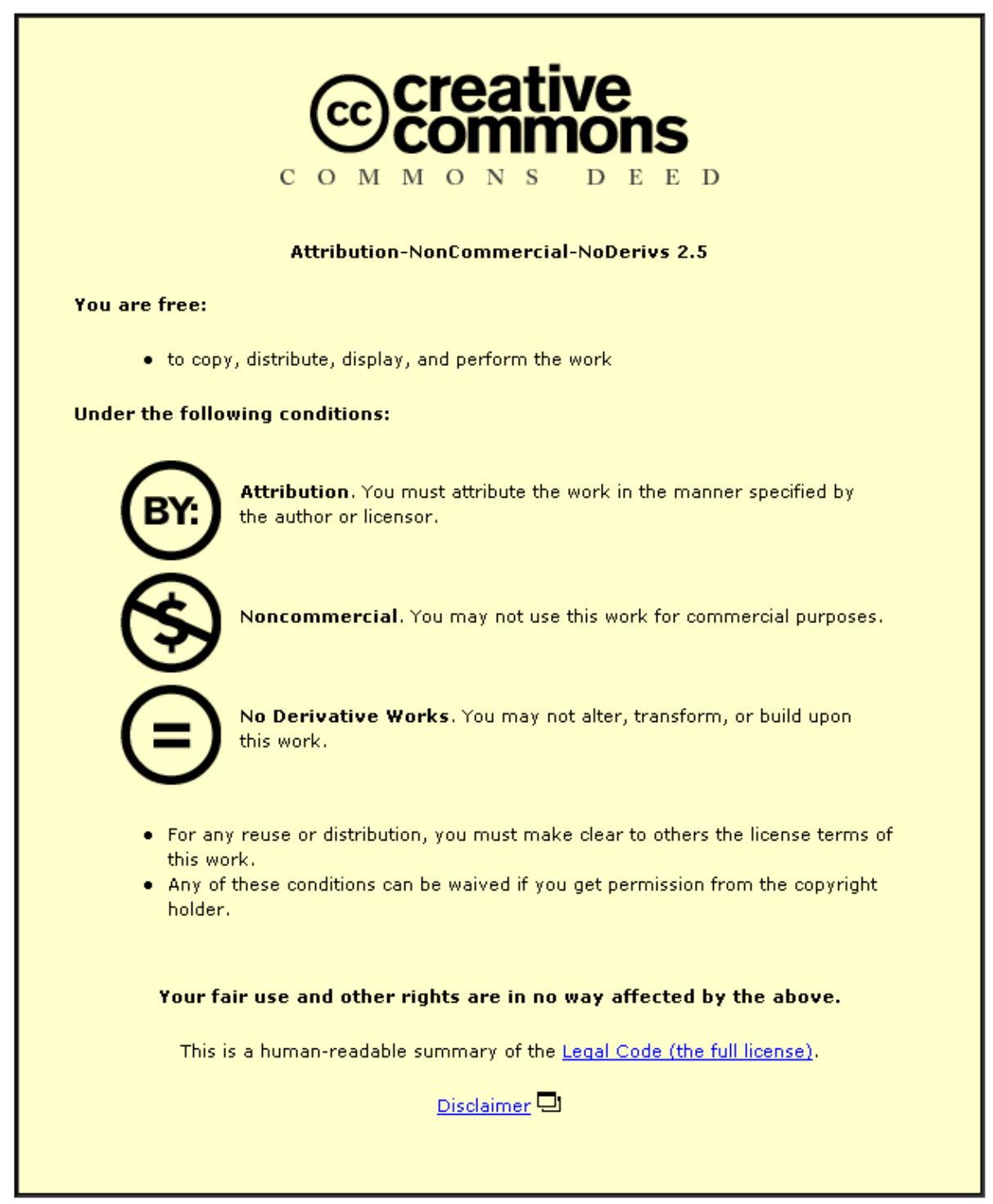

For the full text of this licence, please go to: http://creativecommons.org/licenses/by-nc-nd/2.5/ 
Dixon, N. and Langer, U. (2006) Development of a MSW classification system for the evaluation of mechanical properties. International Journal of Waste Management Science \& Technology, 26, 3, 207-318.

\section{Development of a MSW Classification System for the Evaluation of Mechanical Properties}

\section{Dr Neil Dixon*}

Department of Civil and Building Engineering

Loughborough University, Loughborough LE11 3TU

Email: N.Dixon@lboro.ac.uk ～Tel.: (01509) $228542 \quad$ Fax: (01509) 223945

\section{Ulrich Langer}

Department of Civil and Building Engineering

Loughborough University, Loughborough LE11 3TU

Email: U.Langer@lboro.ac.uk Ｔel.: (01509) 263714133 Fax: (01509) 223981 


\section{Abstract}

To date, sparse information is available on the mechanical properties of municipal solid waste and the results of published work are often hard to compare due to differences in waste composition and therefore properties. To allow comparison, a unified classification system for waste is deemed crucial. Existing classification systems are presented and discussed. For a geotechnical classification, mechanical properties, size, shape and degradability potential of waste components have to be taken into account. A new and improved classification system for waste components is proposed, which complies with the requirements of a geotechnical classification system. It classifies waste components based on (1) their material engineering properties (e.g. shear, compressive and tensile strength), (2) a size distribution of the components, (3) the component shape (reinforcing, compressible and incompressible) and (4) the degree of degradability. The proposed classification system is applied to data from literature and methods for presenting classification information are demonstrated. Further work required to develop a full classification system for waste bodies is highlighted.

Keywords: Municipal solid waste; Classification system; Mechanical properties; Degradability 


\section{Introduction: Why is another waste classification system needed?}

To ensure stability of a construction the physical properties of its components have to be well known. In a landfill, waste presents the largest structural element and often controls both the stability and integrity of the lining system (Jones and Dixon, 2003). However, in spite of this critical role there is a dearth of knowledge on behaviour of waste as an engineering material. It is proposed that a rigorous classification system is required to help explain mechanical behaviour (e.g. compressibility and stability) of waste bodies, to group wastes with similar mechanical properties and to facilitate the exchange and interpretation of measured properties. Given the significant variation in waste materials, and the limited number of researchers and practitioners engaged in measuring mechanical properties of waste, a classification system is deemed crucial to development of a unified framework for waste mechanics, and hence to our ability to design and operate landfills that represent a minimal risk to the environment.

Past experience is a poor guide to future behaviour. Life style changes and the introduction of new legislation (e.g. reductions in biodegradable waste driven by the European Landfill Directive, European Council, 1999) and pre-treatment (e.g. recycling activities) are resulting in significant changes to waste composition. Knowledge of waste components properties is required to evaluate future changes in mechanical properties of waste bodies and hence landfill behaviour.

Waste bodies are heterogeneous; they have anisotropic physical properties (due to placement in layers) and varying biological properties. To enable the assessment of mechanical behaviour of waste bodies it is necessary to investigate the properties of its components. A first step is to develop a classification system that groups components according to their physical and mechanical properties, including an assessment of their potential to influence mechanical behaviour of the waste body. The second step is to 
describe in-situ waste body structures and hence to evaluate mechanical properties of these volumes of waste (e.g. compressibility, shear strength and stiffness). Structure of waste bodies relates to orientation and particle packing of components. For example, foil type components such as paper and plastic may have sub-horizontal orientations as a result of waste placement and compaction in layers.

Whitlow (1983) justifies the need for a classification system and describes the principles for classifying soil as follows.

"The system adopted needs to be sufficiently comprehensive to include all [...] deposits, while still being reasonable, systematic and concise. [...]. Without the use of a classification system, published information or recommendations on design and construction based on the type of material are misleading, and it will be difficult to apply experience gained to future design. Furthermore, unless a system of conventional nomenclature is adopted, conflicting interpretations of the terms used may lead to confusion. [...] A classification system must satisfy a number of conditions:

a) It must incorporate definitive terms that are brief and yet meaningful [...].

b) Its classes and sub-classes must be defined by parameters that are reasonably easy to measure quantitatively.

c) Its classes and sub-classes must group together soils having characteristics that will imply similar engineering properties.”

All of these issues are also important for a waste classification system. In proposing a framework for classification and description of waste materials it is appropriate to follow those developed for soils, although additional properties will also have to be considered.

This paper describes a framework for classifying waste components. It extends and develops a framework for a new classification system proposed by Langer and Dixon (2004). It starts with an overview of existing classification systems for waste. Based on 
this review, recommendations for an improved classification system are made. Subsequently, important characteristic properties of the components essential for a geotechnical classification are emphasised. Application of the proposed classification is demonstrated using data from the literature.

\section{Review of existing waste classification systems for mechanical behaviour}

A number of the existing classification systems are simply based on material groups (e.g., paper, plastic, metal, etc., Siegel et al., 1990) or on the distinction between soil-like and non soil-like, or fibrous, appearance (Manassero et al., 1997; Thomas et al., 1999). These existing classification systems do not fulfil the requirements of a rigorous classification framework as outlined above. Table 1 provides a summary of existing classification systems including the parameters defined. Key elements of these classification systems are considered further.

Landva and Clark (1990) proposed a classification system that differentiates between organic and inorganic components. They subdivided these into putrescible and nonputrescible within the organic components, and degradable (corrodible) and nondegradable within the inorganic components (Fig. 1). Additionally, void-forming constituents within each subdivision, excluding the putrescible group, are highlighted. This system provides detailed information on degradation and compressibility potential of components but does not consider component shape or material properties (e.g. tensile strength of components).

Grisolia et al. (1995) defined degradable, inert and deformable component groups and classified wastes by plotting the percentages of each group in a ternary diagram. This allows comparison of the composition of different wastes. A strength of this system is that it provides information about compressibility and degradability of components. However, 
it is possible for a component to fit into more than one group (e.g. food residues are biodegradable and highly deformable) and again particle shape is not considered.

Kölsch’s (1996) classification system includes material groups, size and dimension of components. The advantage of this system is the possibility for a more detailed examination of component properties, which is consistent with the known large variability of waste component form and properties. The disadvantage is the large amount of data required and the omission of information on degradation potential. Such a detailed system is more appropriate for research purposes than regular practical use.

None of the existing systems fulfil the requirements for a rigorous waste mechanics classification. However, they provide useful criteria. The information required to classify waste components can be summarised as:

- A distinction is required between the material groups (i.e. based on typical component material properties), with dominant groupings established. Information is then required on the proportion (e.g. by weight) of different size components in each material group.

- Knowledge of component shape is required to distinguish between soil-like (threedimensional e.g. granular) and non soil-like (two-dimensional e.g. sheet) components. This allows classification of components in relation to their potential for influencing mechanical behaviour of the waste mass (e.g. compressibility, shear and tensile strength).

- Grading by size is required for each group of components (size assessment of each component).

- An assessment of component compressibility and hence the potential for components to change shape during placement and/or burial.

- An assessment of degradation potential for both organic and inorganic components. 


\section{Elements of a classification system}

\subsection{Description of the components}

The starting point for a classification system is identification of the main waste components by material type. Due to the large variety of materials present in waste, a practical approach is to identify major groups of materials. For example, an American waste composition survey done by the Department of Environmental Quality (1998) used the following main groups: organic, paper, wood, polymer/plastics, metal (Fe/non-Fe), soil-like, ceramic, glass, inerts and rubber. Waste composition is defined by measuring the mass percentage of each material group present in a sample. A significant barrier to the sharing of information on waste behaviour is the use of different groups of materials by those classifying samples used in experimental programmes. In many instances the reasoning behind selection of specific groupings is not explained, and hence the factors influencing measured behaviour can not be fully understood. Fig. 2 shows an American waste composition survey done by Department of Environmental Quality (1998) and an average UK waste composition. The latter is derived from a literature review of composition of UK waste and is based upon the following eight different datasets: Department of the Environment, 1994a; Department of the Environment, 1994b; Dunn, 2002; Green and Jamnejad, 1997; Jotisankasa, 2001; University of Newcastle upon Tyne, 1999; NWET, 2002; University College Northampton, 2000.

\subsection{Mechanical properties of components in material groups}

Selection of appropriate groups requires consideration of component mechanical properties. It is proposed that components are considered in the condition they have on delivery to the landfill site. Definition of this initial state is required because mechanical properties, shape and size of components will change as a result of placement conditions (i.e. compaction) and stresses due to burial, due to the deformability of some particles, and 
in the long-term due to degradation processes. The classification system must provide the possibility for components to change group as a result of these processes. Moreover, the groupings should be appropriate for every type of waste. The following mechanical properties can be considered as a basis for producing component material groupings:

- Shear strength

- Tensile strength

- Compressive strength

- Elongation at break (at given strain)

- Modulus of elasticity

For the material groups initially defined by Department of Environmental Quality (1998), Fig. 3 shows indicative shear and tensile strengths, elongation at break, compressive strength and modulus of elasticity. The data for mechanical properties are derived from various published sources and databases (Cambridge Engineering Selector; Carderelli, 1966; IdeMat, 2002; MatWeb, 2004; Schneider, 1996). These show significant variability. In addition to the average values for components in each material group, the range of values is presented to emphasise variability. It is not intended to use the information in these diagrams to define materials by specific material values, but to highlight the state of variability within groups, and stress similarities and differences of the material groups. This information can be used to identify those groups of materials that can be amalgamated to simplify the classification. In addition, it provides an indication of the groups that could influence specific aspects of waste body mechanical behaviour (e.g. compressibility, shear strength). However, it should be noted that waste body behaviour is also dependant on the overall composition of the waste body and on the in-situ density, structure and stress state. 
For tensile strength, organic matter and paper are the dominant materials (Fig. 3). The high tensile strength of metals has only limited influence due to the low percentage present in this sample of waste. Considering compressive strength, possible groupings of materials could be: ceramics and inerts with a very high compressive strength; glass and metals with a high to medium compressive strength; and paper, wood and polymers/plastics with a low compressive strength. Fig. 3 indicates that the organic and soil-like material possess almost no compressive strength. In the case of soil this is misleading as individual soil grains (i.e. waste components) have a relatively high compressive strength. It is important that the properties of only the components are considered in a classification and not of assemblages of components (i.e. a quantity of soil). The information summarised in Fig. 3 has been used to select the material groups for use in the proposed classification (Section 4).

\subsection{Shape-related subdivision of components}

The following distinction is based on observations of waste components and consideration of mechanical properties of components (e.g. how easily they can be compressed). Assessments have been made about the role material groups could play in mechanical behaviour of the waste body. Further research is required to validate these assessments, as discussed below. It is proposed that the shape of waste components could be characterised by one of two basic groups based on shape-related properties, in conjunction with associated subdivisions:

- Reinforcing components; one-, two-dimensional (e.g. plastic bags, sheets of paper)

- Three-dimensional components

a) Compressible components

- High compressibility (e.g. putrescible materials, plastic packaging) 
- Low compressibility (e.g. beverage cans)

b) Incompressible components (e.g. bricks, pieces of metal)

The subdivision of compressible components is necessary for assessing changes resulting from placement activities (i.e. depositing and compacting the waste) and overburden stresses from additional waste layers. Stressing high compressibility components could lead to shearing and crushing of components, while low compressibility components could remain unaffected during deposition. The simplified distinction between high and low compressibility components provides a solution for consideration of short-term behaviour due to placement and compaction, and long-term behaviour of components in response to increasing overburden stress and creep. However, at present there is insufficient experimental data to enable such a subdivision to be quantified (i.e. to define the threshold stress between high and low compressibility). The threshold should be related to the maximum stress imposed during waste placement and compaction. Further work is required to develop an appropriate simple test for assessing the compressibility of each component and to provide relevant threshold values. Incompressible components are those that will not compress if subjected to the maximum overburden stress in a specific landfill (i.e. in a 50 metre deep landfill the maximum overburden stress will be approximately 500 $\mathrm{kPa})$.

Definition of a component as reinforcing is based on an assessment of the size of reinforcing components (e.g. fibre or foil) in relation to the size of surrounding regular shaped 3-D components (i.e. those particles tending to spherical in shape). Theoretically, reinforcing can result when fibre/foil length exceeds the nominal diameter of the regularly shaped particles. If bonding of reinforcing components between regularly shaped 3-D particles does not occur, then tensile forces in the mixture cannot be generated. For example, Michalowski and Zhao (1996) suggest that the length of the reinforcement must 
be at least one order of magnitude larger than the diameter $\left(d_{50}\right)$ of sand grains for fibrereinforced soils. The relationship between fibre/foil dimensions and size of regular particles for reinforcing behaviour is currently being investigated by the Authors through a laboratory study using controlled synthetic MSW.

With a shape-related subdivision of waste constituents, a grouping of components with similar general mechanical behaviour (i.e. (in-)compressible and reinforcing properties) can be given. This meets the requirements of a geotechnical classification system.

\subsection{Grading of waste - size of components}

A key element of a classification is information on grading. Data from Kölsch (1996) is used to demonstrate a dry mass distribution for waste components including grading. The data shown in Fig. 4 is for a fresh domestic refuse from an urban district. As a result of a separate bio-waste collection the organic content was reduced prior to grading. The waste components were sorted using three different criteria: material type, shape and size. The material groups used were: paper/cardboard; flexible plastics; rigid plastics; metals; minerals; wood/leather; organics and miscellaneous $<40 \mathrm{~mm}$. Although there are some similarities with the groups used by Department of Environmental Quality (1998), there are also significant differences that make it difficult to compare waste types.

The data was re-sorted to adapt it to the new classification framework. Each material group was subdivided based on shape-related properties (i.e. compressible, incompressible and reinforcing components). The final step was to grade components into the following size ranges: $<8 \mathrm{~mm}, 8-40 \mathrm{~mm}, 40-120 \mathrm{~mm}, 120-500 \mathrm{~mm}, 500-1000 \mathrm{~mm},>1000 \mathrm{~mm}$. From Fig. 4, it can be seen that the components forming the largest proportion by weight in this sample are those with sizes in the range $40-120 \mathrm{~mm}$. These are heavy components such as broken glass, stones, etc. and also components defined as reinforcing (e.g. paper and plastic). The fine fraction, $<40 \mathrm{~mm}$, would be higher in areas without pre-treatment to 
reduce organic materials (i.e. due to the presence of coffee grounds, tea bags, food residues, etc.).

An example of subdivision of material groups based on component shapes is shown in Fig. 5 to Fig. 7 for the shape-related subdivision of compressible (30.6\% dry mass), reinforcing (43.4\% dry mass) and incompressible components (26.0\% dry mass), respectively. It has been assumed that the miscellaneous material group initially defined by Kölsch (1996) is composed of compressible and incompressible components in equal shares. This is justified by the observation that this material mixture contains both compressible organic material and incompressible soil-like material, stones, fractions of bricks etc. For incompressible components a clear concentration is visible for the groups of metals, minerals and wood/leather in the size range of $8-500 \mathrm{~mm}$ and for the miscellaneous material with a size less than 40mm (Fig. 5). Reinforcing components show their highest peak for paper/cardboard and flexible plastics between $40 \mathrm{~mm}$ and $500 \mathrm{~mm}$; but reinforcing element also exist in rigid plastics, metals, minerals and wood/leather up to a size $>1000 \mathrm{~mm}$ (Fig. 6). Clear peaks for flexible plastics and miscellaneous material are shown in Fig. 7 for compressive components within the range of $40-120 \mathrm{~mm}$ and $8-40 \mathrm{~mm}$. After applying load, a percentage of these components will change group within the shaperelated subdivision from compressible to reinforcing components (i.e. as they are flattened). It should be noted that this data is for the waste in its initial, pre-placement, condition. The figures demonstrate how detailed information on material group, size, and shape of components can be presented.

\subsection{Degradation potential}

In order to be able to represent changes in classification that occur due to degradation of components, it is necessary to provide information on degradation potential. The subdivisions proposed by Landva and Clark (1990), and discussed above, are considered to 
provide an appropriate framework. For assessment of degradation potential, it is important to distinguish between short-term, medium-term and long-term degradation rates. Paar (2000) specifies the hierarchy of biodegradable substances (Table 2). As the largest degradation alteration of waste components occurs by bio-degradation, the framework introduced here only considers this. Other degradation processes like corrosion and dissolution or other chemical reactions depend on the surrounding milieu. For physical decay or weathering processes, temperature, water content and water and solids movement play important roles. There is inadequate information in the literature to develop this aspect of waste behaviour further at the present time.

The distinction of the different stages of degradation can also be linked to different materials. For example, kitchen waste (for the most part vegetable residue or the like) degrades more rapidly than paper. A comprehensive classification system should include these factors. There are various methods available to assess the organic content. Methods such as the loss of ignition and the Total Organic Content (TOC) only provide information on the general organic fraction and the amount of organic carbon, respectively, and not on the degradable organic fraction and carbon, which is required if using the Paar (2000) subdivision. However, in conjunction with the Biological Oxygen Demand, conclusions can be made about the biological activity of the waste.

\section{Proposed classification framework}

A framework of waste classification is shown in Fig. 8 and Fig. 9. The procedure of classifying waste components is presented in Fig. 8; Fig. 9 demonstrates the application of the framework. The application considers the state of waste components at three stages during landfilling: as delivered to site, following placement and in the long-term following degradation. Components of a waste sample are examined to obtain information on: material type, shape and size. This would typically be achieved through a combination of 
visual assessment of material type and properties, measurement (e.g. size and shape) and estimation of degradation potential (i.e. related to material type. Based on the material property information, components can be grouped in order to minimise the number of material categories. Information about material properties and shape of components is used to group them according to whether they are compressible, incompressible or reinforcing. An overall grading for each material group in each of the shape-related subdivisions is then obtained. The subdivisions are then reviewed and modified, if required, by taking into considering the relative size of reinforcing components to regular shaped components as discussed above. Finally, the degradation potential of components in each shape-related material group is defined.

Unlike soil, waste consists of components with a wide range of material properties and this complicates the conventional presentation of data. In addition, the issue of biodegradation is crucial for waste. Therefore, a revised format for presenting information on component material type, shape, size, grading and degradation potential is proposed. Fig. 10 shows an example, fictitious, diagram for a shape-related subdivision of the waste, to demonstrate and explain the format used to present real data in subsequent figures (Fig. 11 to Fig. 13).

Fig. 10 shows grading curves for the three different material groups (material 1,2, and 3). The upper curve, denoted by a thick black line, gives the cumulative grading for the combined material groups forming the shape-related subdivision. The grading lines below this can be used to calculate the cumulative gradings for each material group. For example as shown in Fig. 10, the size range of $>120 \mathrm{~mm}$ represents $73 \%$ of the overall material mass and is composed of $32.2 \%$ material 1, 24.3\% (56.5\% minus 32.2\%) of material 2 and $16.5 \%$ (73\% minus $56.5 \%$ ) of material 3 . The cumulative dry mass percentage of a material group for a given component size is simply the difference between the cumulative 
values of the material groups plotted immediately above and below. In this manner, computed values are related to the shape-related subdivision mass percentage of $100 \%$.

Information on degradability potential is provided in the column on the right hand side of Fig. 10, where the percentage of degradable and non-degradable content for each material group is related to the total mass of waste in this shape related subdivision. Sections of the column are used to represent each material group, with the height based on the percentage of that group as a proportion of the total sample (i.e. the three material groups in this example add up to $100 \%$ of the sample, with material 1 forming $41.1 \%$, material 2 forming $33.9 \%$ and material 3 forming $25 \%$ of the total). If there is biologically degradable material present in a group, the information is represented by a grey section of the column with the percentage shown by the height (i.e. in relation to the overall mass of the shape related sample), and the white section represents the inert percentage. The total percentage of degradable material present in a shape-related subdivision is obtained from the sum of the grey sections of the column. For example, in Fig. 10 the total degradable material in this subdivision is $43.3 \%$ (30.8\% from material 1, 0\% from material 2 and $12.5 \%$ from material 3). The information on degradation potential enables an assessment of possible mass reduction of materials due to degradation, and thus the reduction in proportion of the entire waste sample composed of the shape-related subgroups. This information can be used to revise the classification of the waste for the long-term condition when degradation is complete.

The data produced by Kölsch (1996) is used to demonstrate data analysis and classification of an initial state before waste placement. Information for components in the incompressible, reinforcing and compressible shape-related subdivisions is presented in Fig. 11 to Fig. 13 respectively. These figures show the selected material groups, an overall grading of components in the particular shape-related subdivision, gradings for 
components in each material group and degradation potential for components forming each material group, as discussed above.

The data produced by Kölsch (1996) and re-analysed above can be used to classify the waste components in their initial state (i.e. as delivered to site) based on percentages of the shape-related subdivisions, as shown in Table 3 and Fig. 14. In addition, this diagram can be used to demonstrate changes in classification resulting from waste placement, which causes compression of some components, and in the long-term following degradation of some components. In Fig. 14 the initial state is derived directly from the original shape and material properties data. For the potential state after placement, it has been assumed that the percentage of the reinforcing and incompressible components both increase due to the compression of highly compressible components such as paper, flexible plastic packaging and organic materials. A distinction was made between material sizes $<40 \mathrm{~mm}$ and $>40 \mathrm{~mm}$, and the smaller sized components were assumed to have an insignificant effect on reinforcement (i.e. based on the ratio between the size of reinforcing and regular-shaped components as discussed above); consequently they were reassigned to compressible and incompressible components. Degradation was not taken into account for the waste state following placement due to the fact that placement is by definition a short-term event. Stronger materials such as rigid plastics, wood/leather, and the defined part of the miscellaneous material were assumed to remain in their initial state.

The final state of the waste has been calculated based on the percentage of materials in each shape-related subdivision with potential to degrade. A loss of mass due to methane and carbon dioxide generation and the alteration of organic into mineral matter was calculated using values for the degradation potential of components (Table 4, after Fricke et al., 1999). The remaining compressible components in particular material groups (e.g. rigid plastic, wood/leather and miscellaneous) were assumed to become incompressible 
(sized $<40 \mathrm{~mm}$ ) and reinforcing (sized $>40 \mathrm{~mm}$ ) due to overburden stress. It is assumed that the overburden stress exceeds the maximum compressive strength of these components and that this therefore causes flattening. Due to the material characteristics of metals and minerals, these groups stayed in their initial state. The use of the ternary diagram requires the presentation of the shape-related subdivisions as percentages as shown in Table 3, which means that the loss of mass is not shown, due to the fact that the sum of the shaperelated subgroups always has to equal $100 \%$. In fact there is a loss of mass in each of the three groups due to degradation.

A more comprehensive waste classification reflecting placement and long-term conditions requires a detailed investigation of potential changes in grading, shape and mechanical properties of the materials due to biodegradation, compression and creep.

\section{Conclusions}

A framework for classifying components of waste has been developed and presented. It is proposed that it can be used to provide information on the state of components as delivered to site, following placement and in the long-term following degradation. The presented framework proposes classifying waste components based on (1) their material type and hence engineering properties, (2) the component shape, (3) the size of the components and (4) the degradation potential. The method is likely to be of use to researchers involved in sharing and interpreting experimental data on mechanical properties of waste. This will aid the development of a consistent understanding of waste mechanics. This field of study is currently dominated by varying interpretations leading to inconsistent conclusions.

Further work is required to relate classification of waste components to mechanical behaviour of waste bodies (e.g. in relation to shear strength, compressibility, stiffness) and in respect to their degradability. This includes the need to develop protocols for describing the structure of waste bodies (i.e. orientation of components and particle packing 
arrangements). In addition, the influence of water should be incorporated into the classification system. The influence of water on mechanical properties of components (e.g. shear strength of paper) and hence mechanical behaviour of the waste bodies is rarely considered, except for effective stresses. Such research is required urgently.

The authors are currently conducting waste classification trials to validate the proposed framework and a programme of compression and shear tests is in progress to further develop the definition of reinforcing and compressible components and to investigate the relationship between component classification and mechanical behaviour of the waste body. 


\section{References}

Cambridge Engineering Selector (CES) [CD-Rom], Cambridge: Granta Design

Cardarelli, F., 1966, Materials handbook: a concise desktop reference. Springer, London c2000.

Department of Environmental Quality, 1998. Oregon Solid Waste Characterization and Composition 1998. Oregon; available at:

http://www.deq.state.or.us/wmc/solwaste/wcrep1998 [accessed: February 17th, 2004].

Department of the Environment, 1994a. The Technical Aspects of Controlled Waste Management - National Household Waste Analysis Project - Phase 2 - Report on Further Composition and Weight Data. Waste Technical Division, London, CWM 086/94.

Department of the Environment, 1994b. The Technical Aspects of Controlled Waste Management - National Household Waste Analysis Project - Phase 2 Volume 1 Report on Composition and Weight Data. Waste Technical Division, London, CWM 082/94.

Dunn, R., 2002. Pilot Study on the Composition of Municipal Solid Waste in Wales. Waste 2002, Integrated Waste Management and Pollution Control: Research, Policy and Practice, Stratford-upon-Avon, UK. 221-227.

European Council, 1999. Council Directive of 26 April 1999 on the Landfill of Waste (1999/31/EC). Official Journal of the European Communities; Council of the European Community L182(1).

Fricke, K., Müller, W., Bartetzko, C., Einzmann, U., Franke, J., Heckenkamp, G., KellnerAschenbrenner, K., Kölbl, R., Mellies, R., Niesar, M., Wallmann, R. and Zipfel, H., 1999. Biological Pre-treatment of Waste for Landfills: Stabilisation of Residual Waste by Mechanical and Biological Pre-treatment and Effects on Landfilling. German 
Federal Ministry of Education and Research (BMBF), Witzenhausen, Germany, 1480945. Extended Final Version (in German).

Green, D.C. and Jamnejad, G., 1997. Settlement Characteristics of Domestic Waste. Conference on Contaminated Ground, Cardiff, Wales, British Geotechnical Society. 319-324.

Grisolia, M., Napoleoni, Q. and Tancredi, G., 1995. Contribution to a Technical Classification of MSW. 5th International Landfill Symposium, S. Margherita di Pula, Cagliari, Italy, CISA. 703-710.

IdeMat [online], 2002. Delft, The Netherlands: University of Technology; Faculty of Design, Engineering and Production, http://www.io.tudelft.nl/research/dfs/idemat/Onl_db/od_frame.htm [accessed: October 27th, 2004].

Jones, D.R.V. and Dixon, N., 2003. Stability of Landfill Lining Systems: Report I, Literature Review. Environment Agency, P1-385. R\&D Technical report. Jotisankasa, A., 2001. Evaluating the Parameters that Control the Stability of Landfills. MSc Department of Civil and Environmental Engineering, Imperial College of Science, Technology and Medicine, London (unpublished).

Kölsch, F., 1996. The Influence of Fibrous Constituents on Shear Strength of Municipal Solid Waste. Ph.D. Thesis Leichtweiss-Institut, Technische Universität Braunschweig, Brauschweig, Germany (in German).

Landva, A.O. and Clark, J.I., 1990. Geotechnics of Waste Fill - Theory and Practice. ASTM STP 1070; Geotechnics of Waste Fill - Theory and Practice. Landva, A.O. and Knowles, G.D. Philadelphia, USA, American Society for Testing and Materials: 86103. 
Langer, U. and Dixon, N., 2004. Mechanical Properties of MSW: Development of a Classification System. 4th British Geotechnical Association Geoenvironmental Engineering Conference; Integrated Management of Groundwater and Contaminated Land, Stratford-upon-Avon, UK, Thomas Telford, London. 267-274.

Manassero, M., Van Impe, W.F. and Bouazza, A., 1997. Waste Disposal and Containment. Environmental Geotechnics. Kamon, M. Rotterdam, Balkema, A.A.: 1425-1474.

MatWeb [online], 2004. MatWeb - The Online Materials Information Resource. Christiansburg, VA USA: Automation Creations, Inc., http://www.matweb.com or http://www.matls.com.

Michalowski, R.L. and Zhao, A., 1996. Failure of Fiber-Reinforced Granular Soils. Journal of Geotechnical Engineering 122(3): ASCE, 226-234.

NWET, 2002. Waste Characterisation Study Results. Northwest Environmental Trust, Ltd, Trust News 2(1): 11-14.

Paar, S., 2000. The Chimney Aeration Technique - A Technique for Ventilation of Open Rotting Heaps Utilising the Thermal Lift. Ph.D. Thesis Fakultät für Maschinenwesen, Technische Universität Dresden, Dresden, Germany (in German).

Schneider, K.-J., 1996. Bautabellen für Ingenieure mit europäischen und internationalen Vorschriften. Werner-Verlag, Düsseldorf, Germany. In German.

Siegel, R.A., Robertson, R.J. and Anderson, D.G., 1990. Slope Stability Investigations at a Landill in Southern California. ASTM STP 1070; Geotechnics of Waste Fill - Theory and Practice. Landva, A.O. and Knowles, G.D. Philadelphia, USA, American Society for Testing and Materials: 259-284.

Thomas, S., Aboura, A.A., Gourc, J.P., Gotteland, P., Billard, H., Delineau, T., Gisbert, T., Ouvry, J.F. and Vuillemin, M., 1999. An In Situ Waste Mechanical Experimentation on 
a French Landfill. 7th International Landfill Symposium, S. Margherita di Pula, Cagliari, Italy, CISA. 445-452.

Turczynski, U., 1988. Geotechnical Aspects of Building Multicomponent-Landfills. Ph.D. Thesis Bergakademie, Freiberg (Sachsen), Germany.

University College Northampton, 2000. Forward to the Future: Issues for Domestic Waste Minimisation; Examples from Northamptonshire; available at: http://oldweb.northampton.ac.uk/aps/env/waste_min_guide/shanksproject.html [accessed: February 17th, 2004].

University of Newcastle upon Tyne, 1999. Workshop about the Case Study of the Byker Incinerator. School of Chemical Engineering and Advanced Materials; available at: http://www.ncl.ac.uk/sustain/case/bykercase/byker.htm [accessed: February 17th, 2004].

Whitlow, R., 1983. Basic Soil Mechanics. 4th Edition 2001, Pearson Education Limited. 


\section{Tables}

Table 1: Overview of existing classification systems

\begin{tabular}{|c|c|c|}
\hline Author & Basis for Differentiation & Parameters Used for Differentiation \\
\hline Turczynski (1988) & Waste type & $\begin{array}{l}\text { Density, shear parameters, liquid/plastic } \\
\text { limit, permeability }\end{array}$ \\
\hline Siegel et al. (1990) & Material groups & Part of composition \\
\hline $\begin{array}{l}\text { Landva and Clark } \\
\text { (1990) }\end{array}$ & $\begin{array}{l}\text { Organic, inorganic } \\
\text { materials }\end{array}$ & $\begin{array}{l}\text { Degradability (easily, slowly, non) } \\
\text { Shape (hollow, platy, elongated, bulky) }\end{array}$ \\
\hline Grisolia et al. (1995) & $\begin{array}{l}\text { Degradable, inert, de- } \\
\text { formable material groups }\end{array}$ & Strength, deformability, degradability \\
\hline Kölsch (1996) & Material groups & Size, dimension \\
\hline $\begin{array}{l}\text { Manassero et al. } \\
\text { (1997) }\end{array}$ & Soil-like, other & Index properties \\
\hline Thomas et al. (1999) & Soil-like, non soil-like & Material groups \\
\hline
\end{tabular}


Table 2: Degradation hierarchy of substances after Paar (2000)

Substance

Sugar, starch, protein, fat

Hemicelluloses, celluloses, wax, synthetic oil

Lignin, resin

Leather, rubber, plastics
Degradability

Easy

Medium difficult

Difficult

Very difficult to non-degradable 
Table 3: Percentage values of shape-related subdivisions used to define initial, post placement and final states on the ternary classification diagram (Fig. 14)

\begin{tabular}{lcccc} 
& \multicolumn{3}{c}{ Shape-related Subdivisions by Dry Mass } \\
\cline { 2 - 5 } State & Reinforcing & Incompressible & Compressible & Sum \\
\cline { 2 - 5 } & {$[\%]$} & {$[\%]$} & {$[\%]$} & {$[\%]$} \\
\hline Initial State & 43.4 & 26.0 & 30.6 & 100 \\
\hline Potential State after Placement & 56.3 & 28.2 & 15.5 & 100 \\
\hline Potential Final State relative & 52.9 & 37.1 & 0.0 & 90 \\
\hline Potential Final State absolute & 58.7 & 41.3 & 0.0 & 100
\end{tabular}


Table 4: Values for the biodegradable part of waste components (after Fricke et al., 1999)

\begin{tabular}{lc} 
Material Groups & Degradation Potential by Dry Mass [\%] \\
\hline \hline Paper/cardboard & 76 \\
\hline Flexible plastics & 0 \\
\hline Rigid plastics & 23 \\
\hline Metals & 0 \\
\hline Minerals & 0 \\
\hline Wood/leather & 85 \\
\hline Organics & 76 \\
\hline Miscellaneous & 28
\end{tabular}




\section{Figures}

\section{Organic}

\begin{tabular}{|c|}
\hline Putrescible \\
(monomers and low \\
resistance polymers, \\
readily biodegradable)
\end{tabular}

Food waste

Garden waste

Animal waste

Material contaminated

by such waste

Non-putrescible
(highly resistant
polymers, slowly
biodegradable)

\section{Paper}

Wood

Textiles

Leather

Plastic, Rubber

Paint, Oil, Grease,

Chemicals, Organic

Sludge

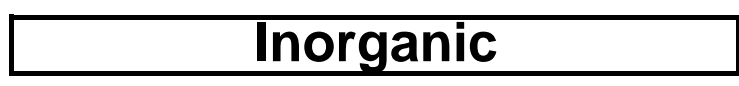

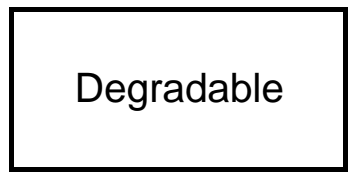

Metals

(corrodible to varying degrees)

\section{Non-degradable}

Glass, Ceramics

Mineral soil, Rubble

Tailings, Slimes

Ash

Concrete, Masonry

(Construction debris)

Fig. 1: Waste classification (after Landva and Clark, 1990)

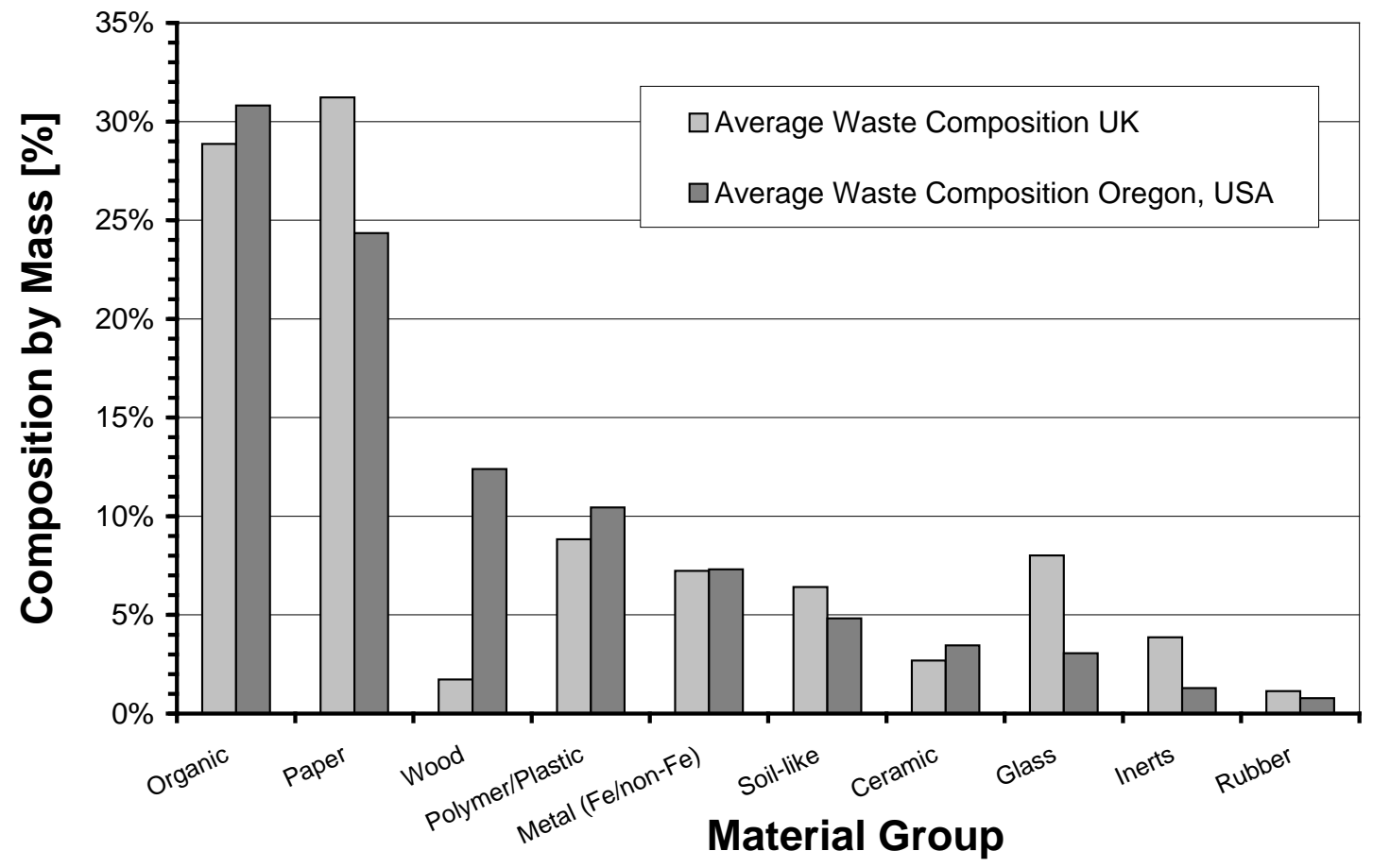

Fig. 2: Waste composition from the USA (Oregon Department of Environmental Quality, 1998) and the UK (estimated from various composition studies, see text for references) 

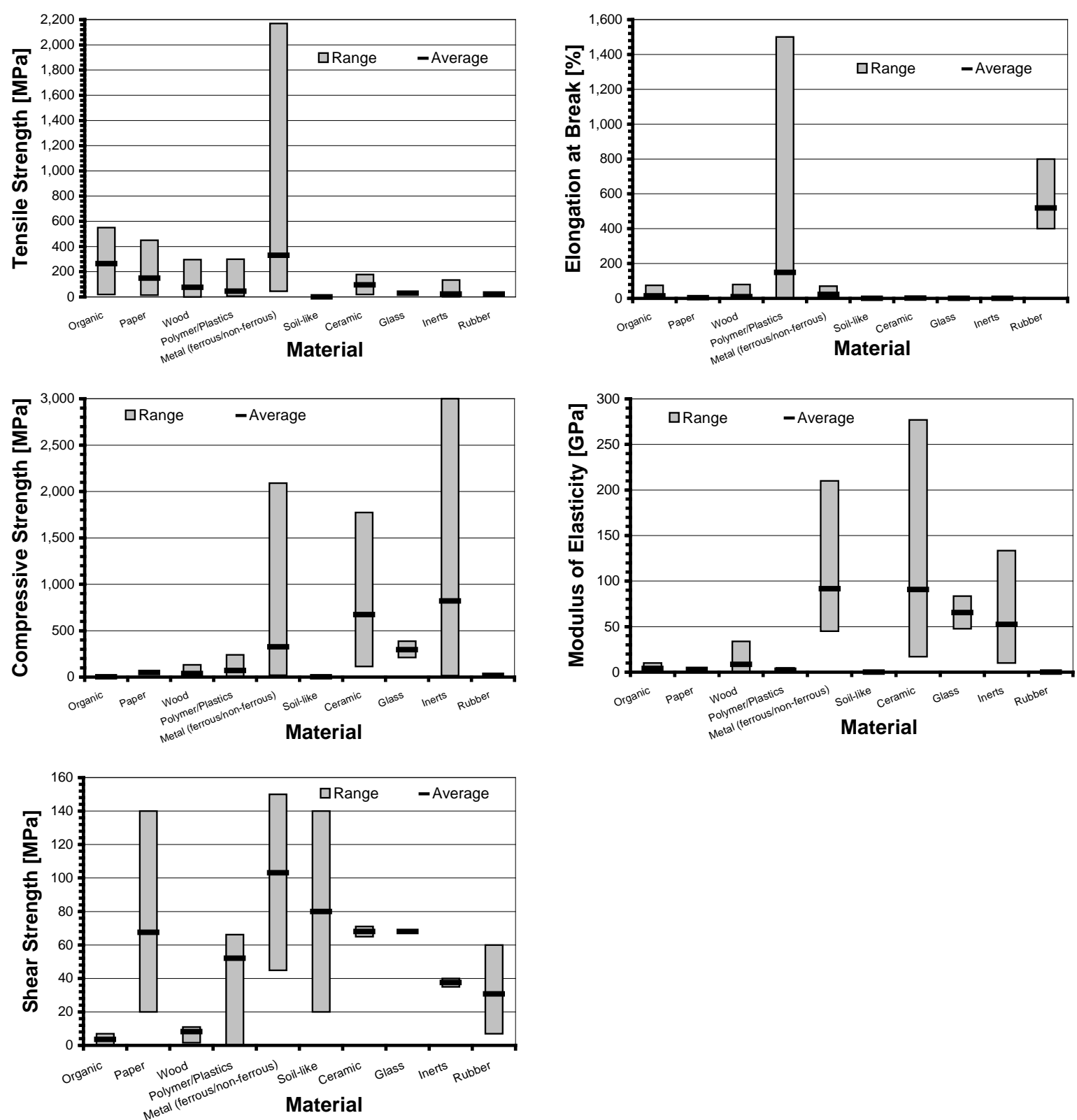

Fig. 3: Minimum-maximum range and average values of mechanical properties for components in selected material groups from sources listed in the text 


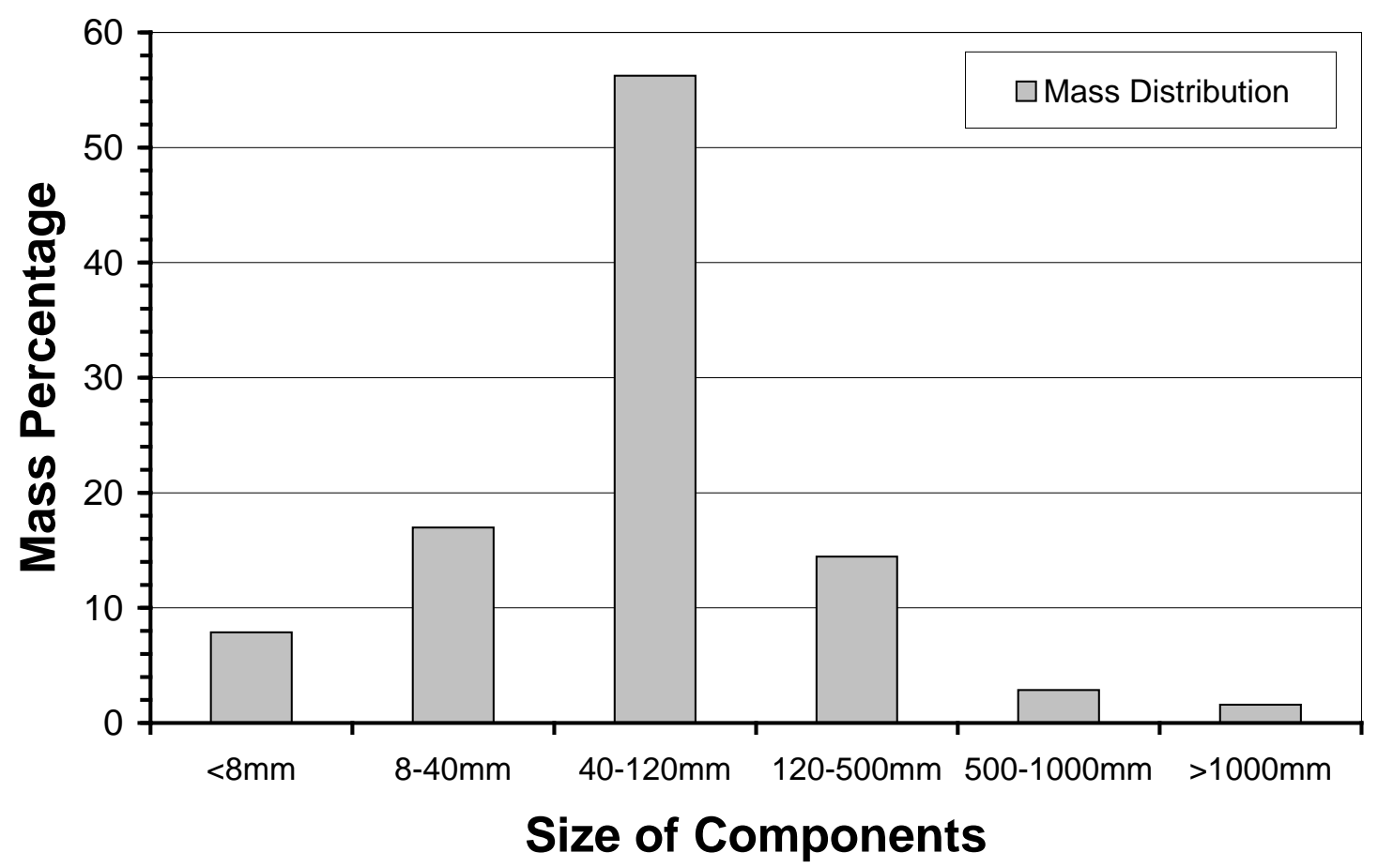

Fig. 4: $\quad$ Mass distribution based on size of the components (after Kölsch, 1996)

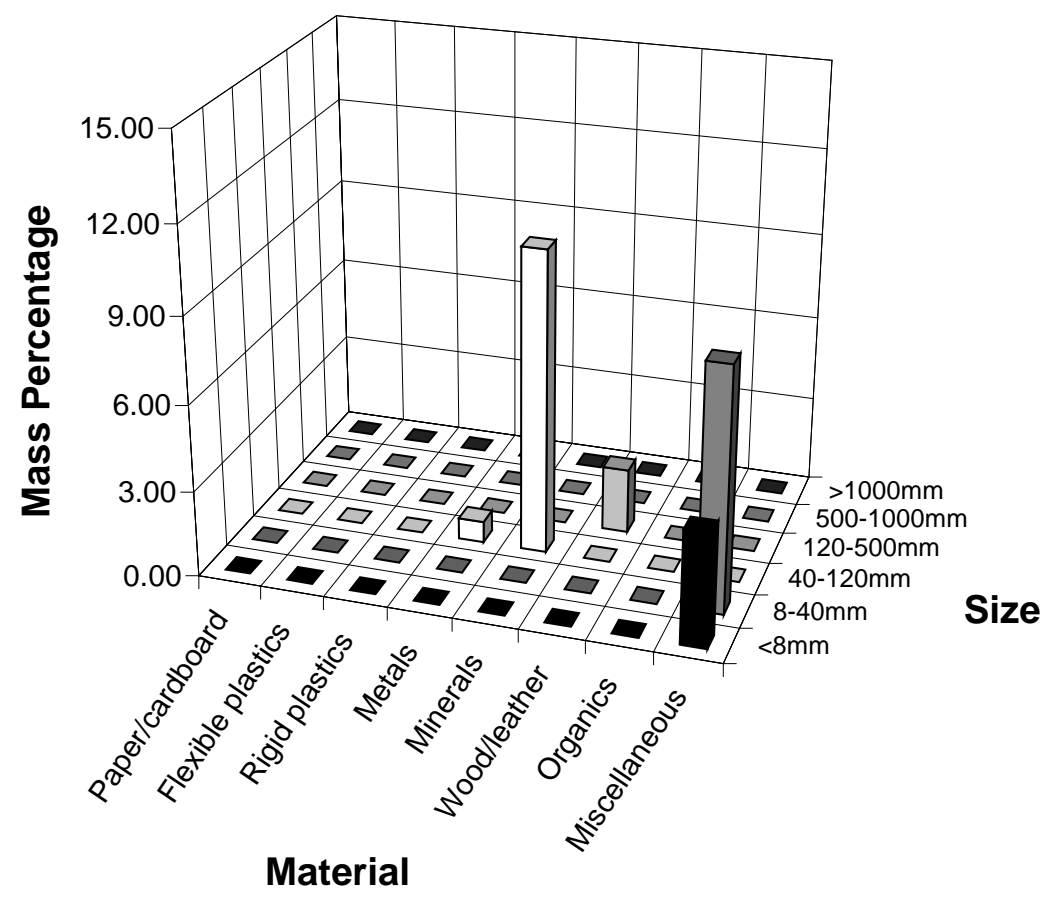

Fig. 5: Mass distribution for incompressible components (data from Kölsch, 1996; with data for miscellaneous material estimated by the Authors) 


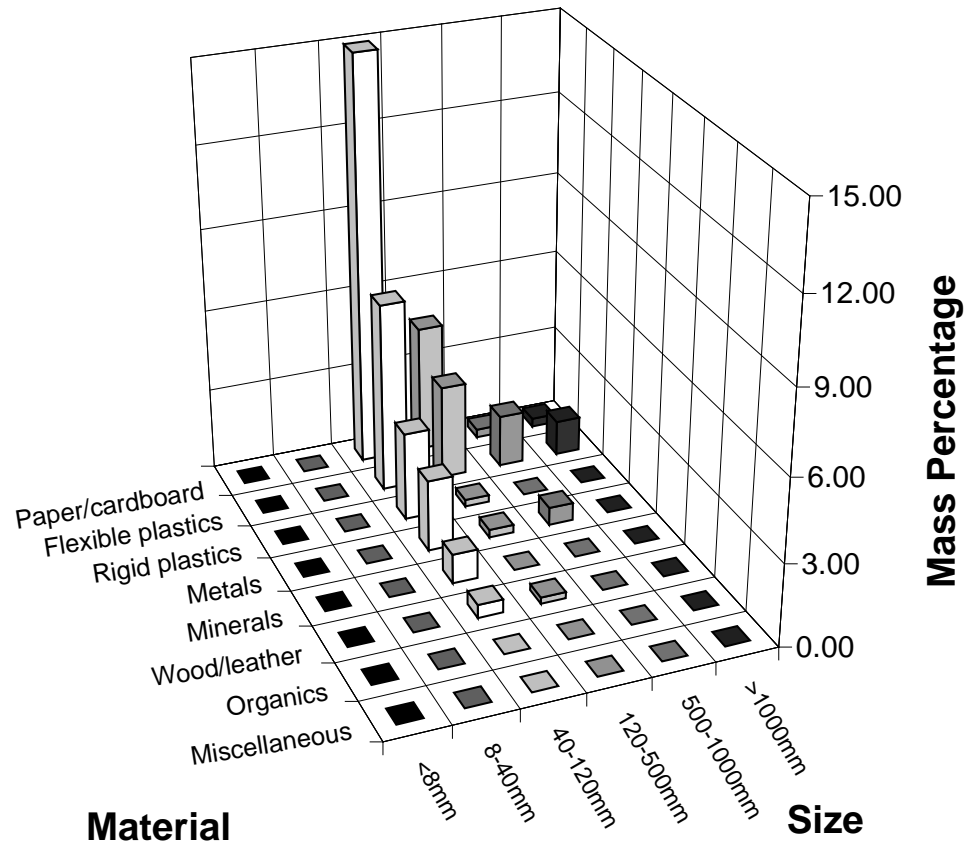

Fig. 6: $\quad$ Mass distribution for reinforcing components (data from Kölsch, 1996)

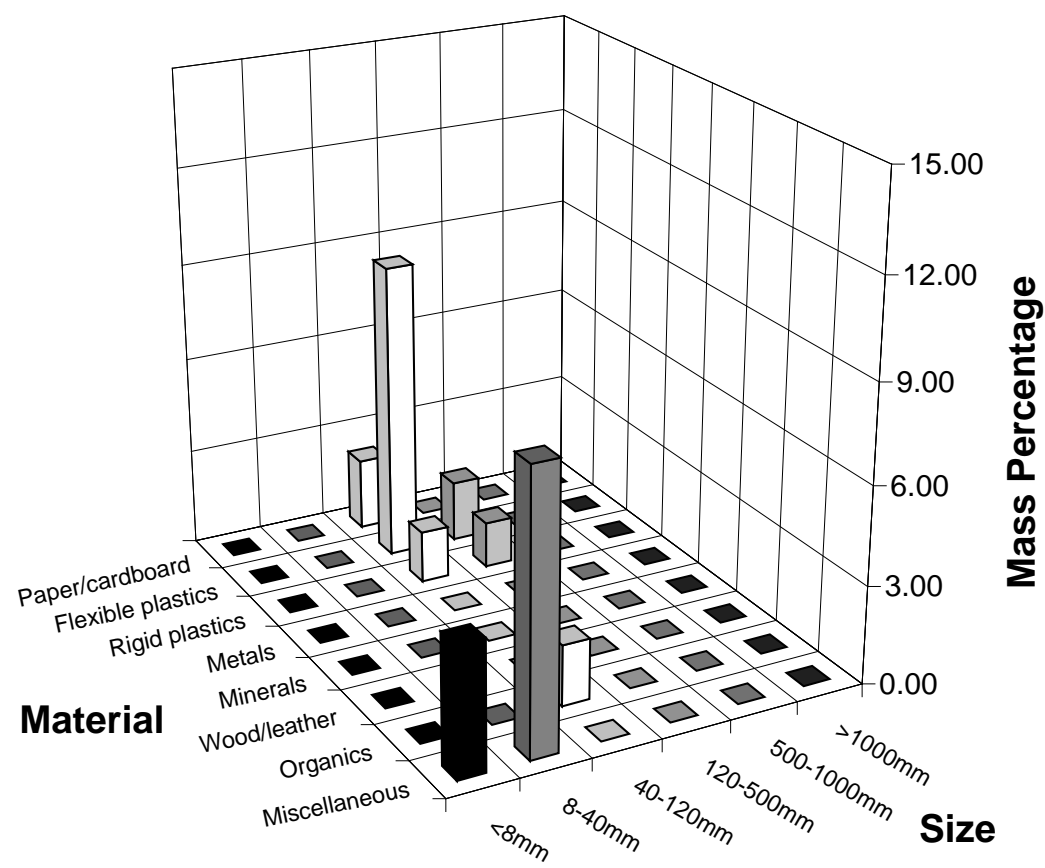

Fig. 7: Mass distribution for compressible components (data from Kölsch, 1996; data for miscellaneous material estimated by the Authors) 


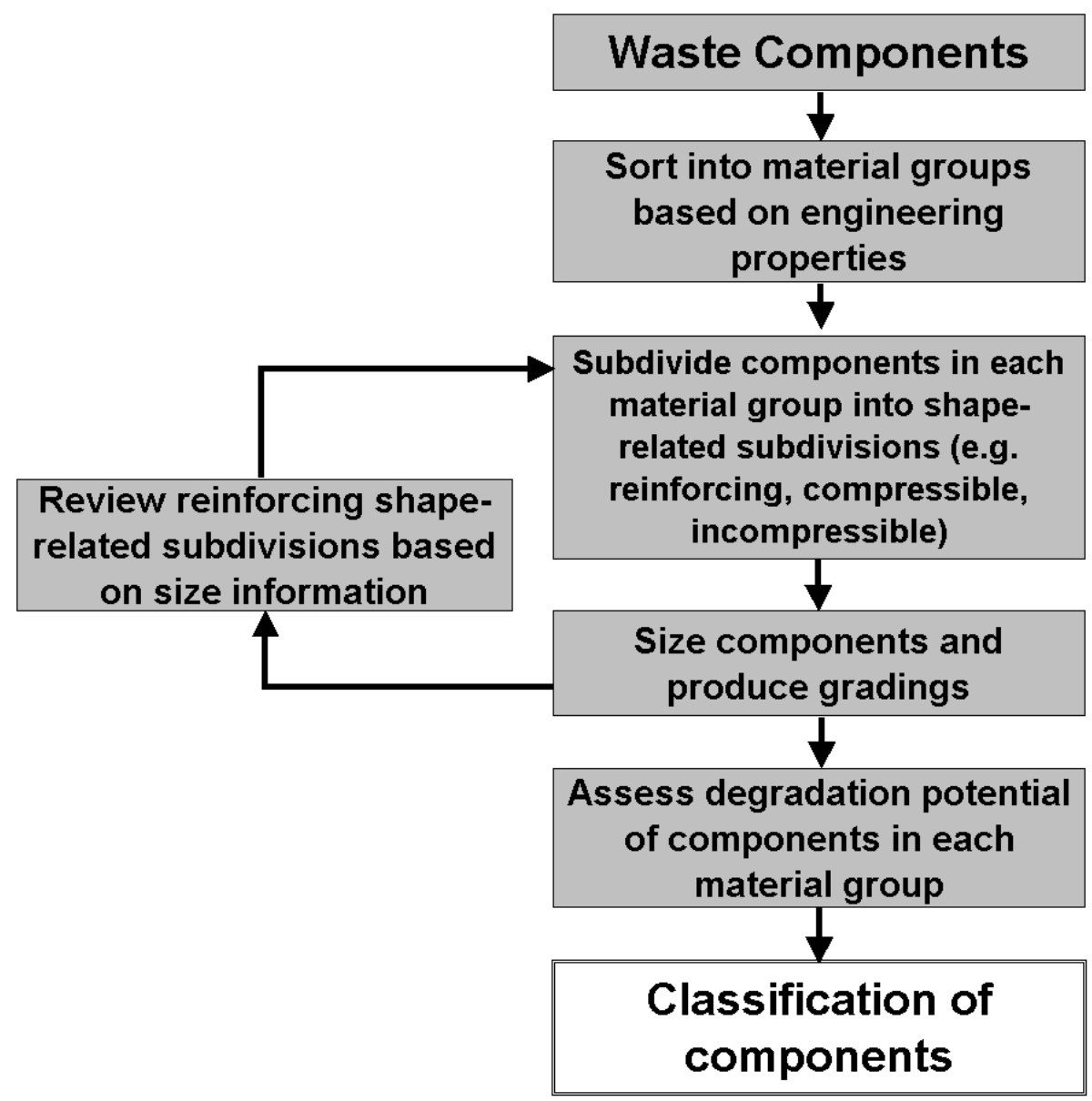

Fig. 8: $\quad$ Procedure of the proposed classification framework

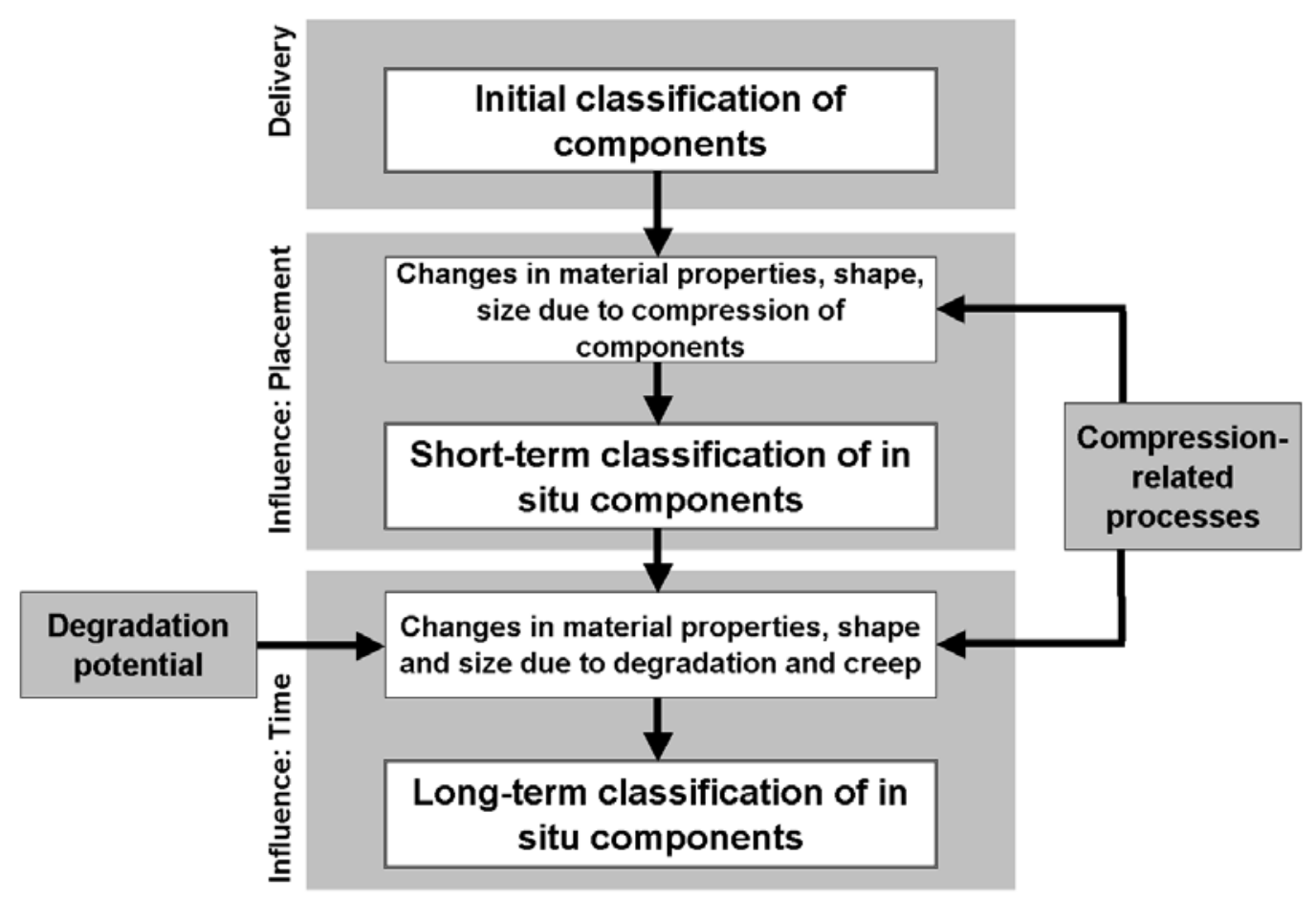

Fig. 9: Application of the proposed classification framework 


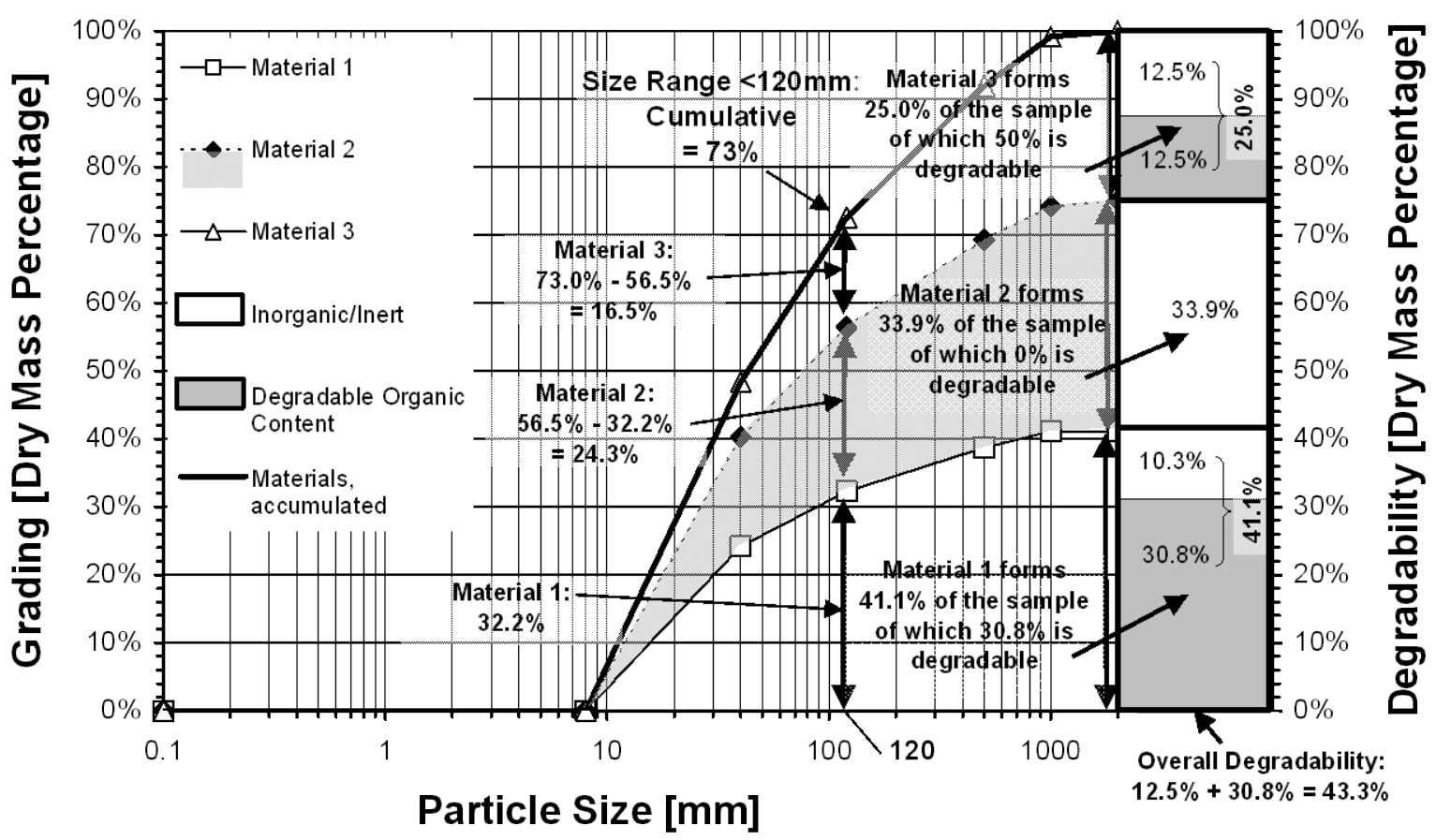

Fig. 10: Example graph demonstrating presentation of data relevant for classification

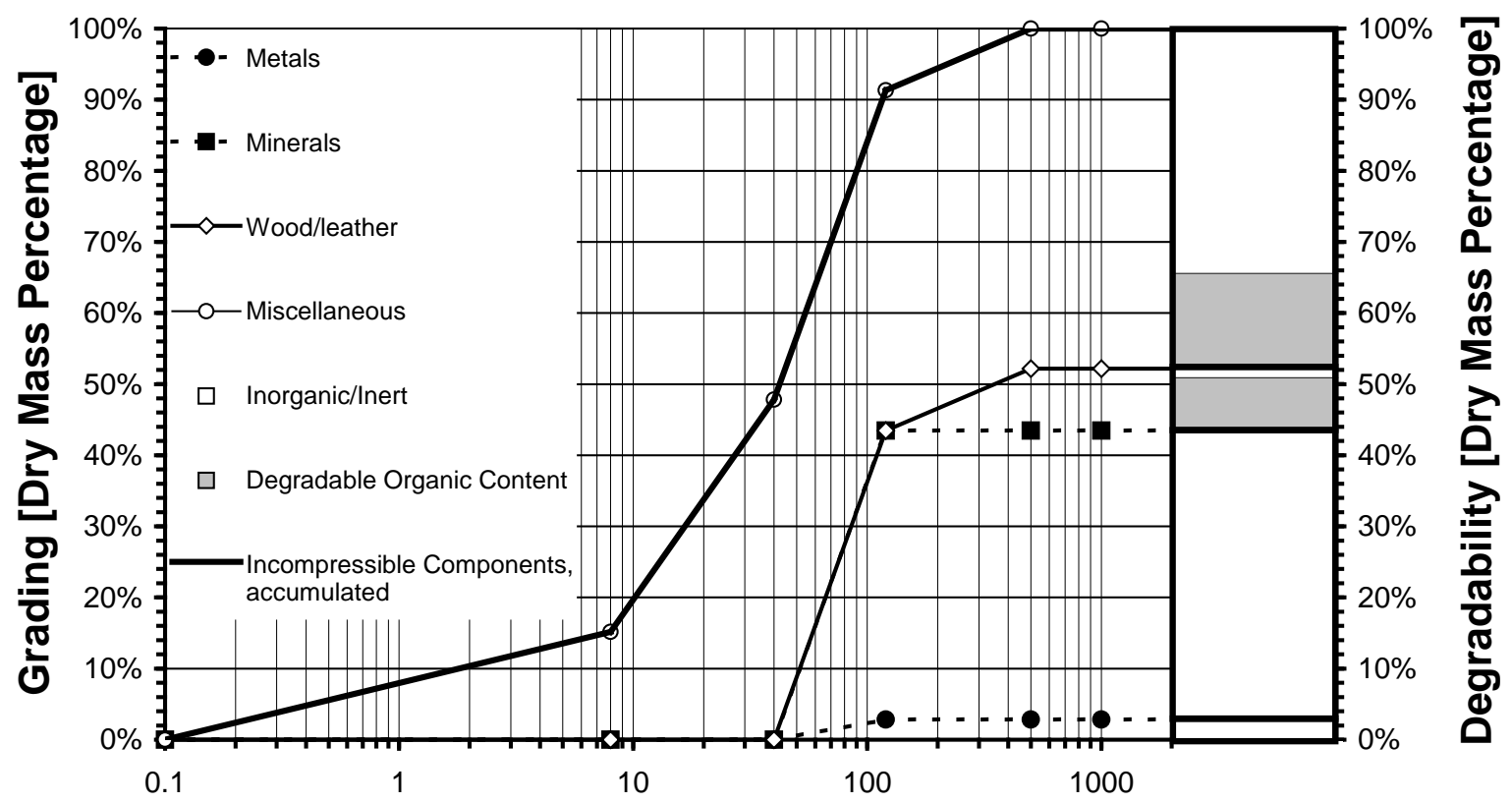

Particle Size [mm]

Fig. 11: Incompressible components: Material groups, gradings, organic content of the material groups related to $100 \%$ of the overall sample mass (data from Kölsch, 1996; data for miscellaneous material modified by the Authors) 


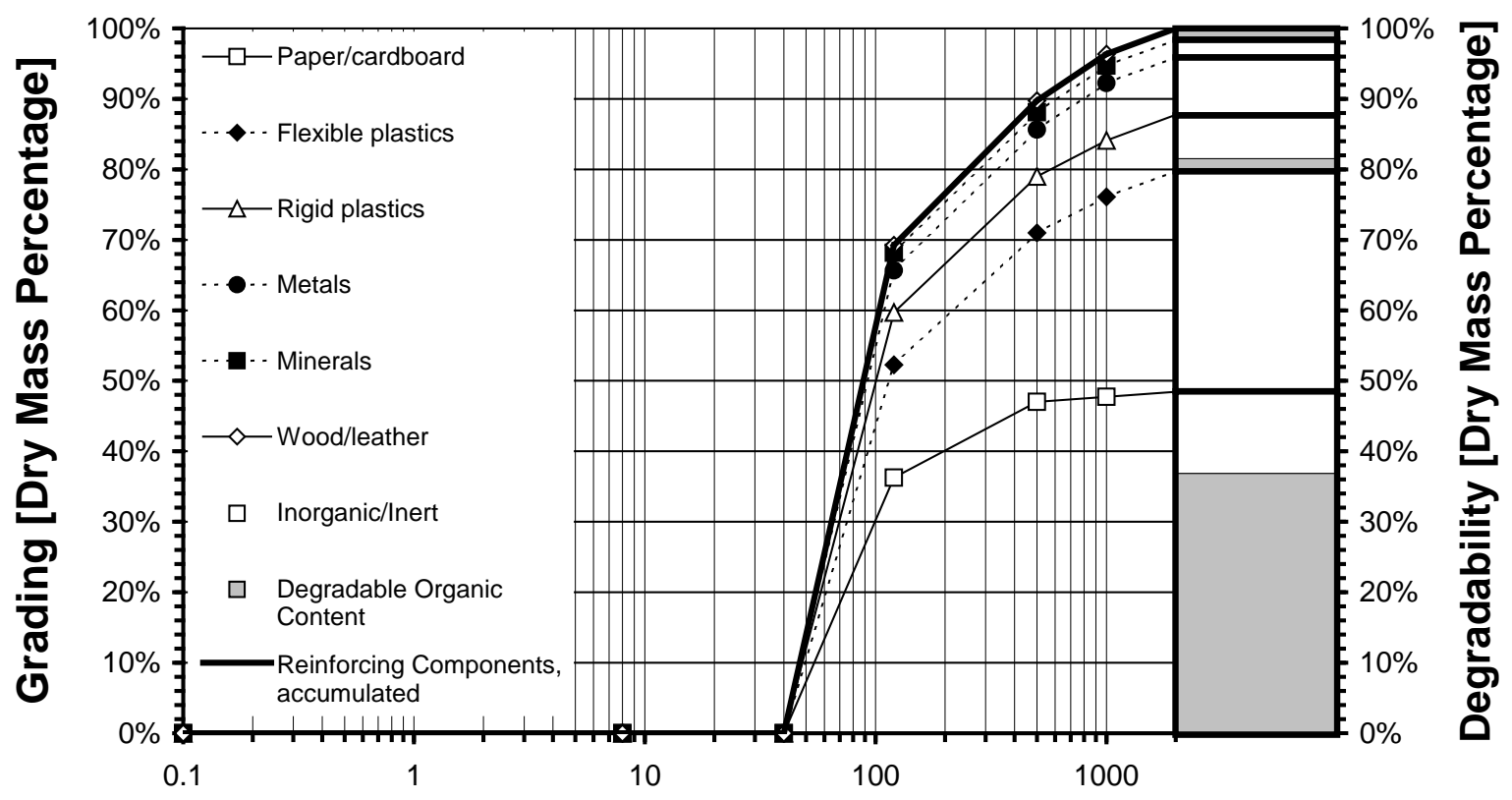

Particle Size $[\mathrm{mm}]$

Fig. 12: Reinforcing components: Material groups, gradings, organic content of the material groups related to $100 \%$ of the overall sample mass (data from Kölsch, 1996)

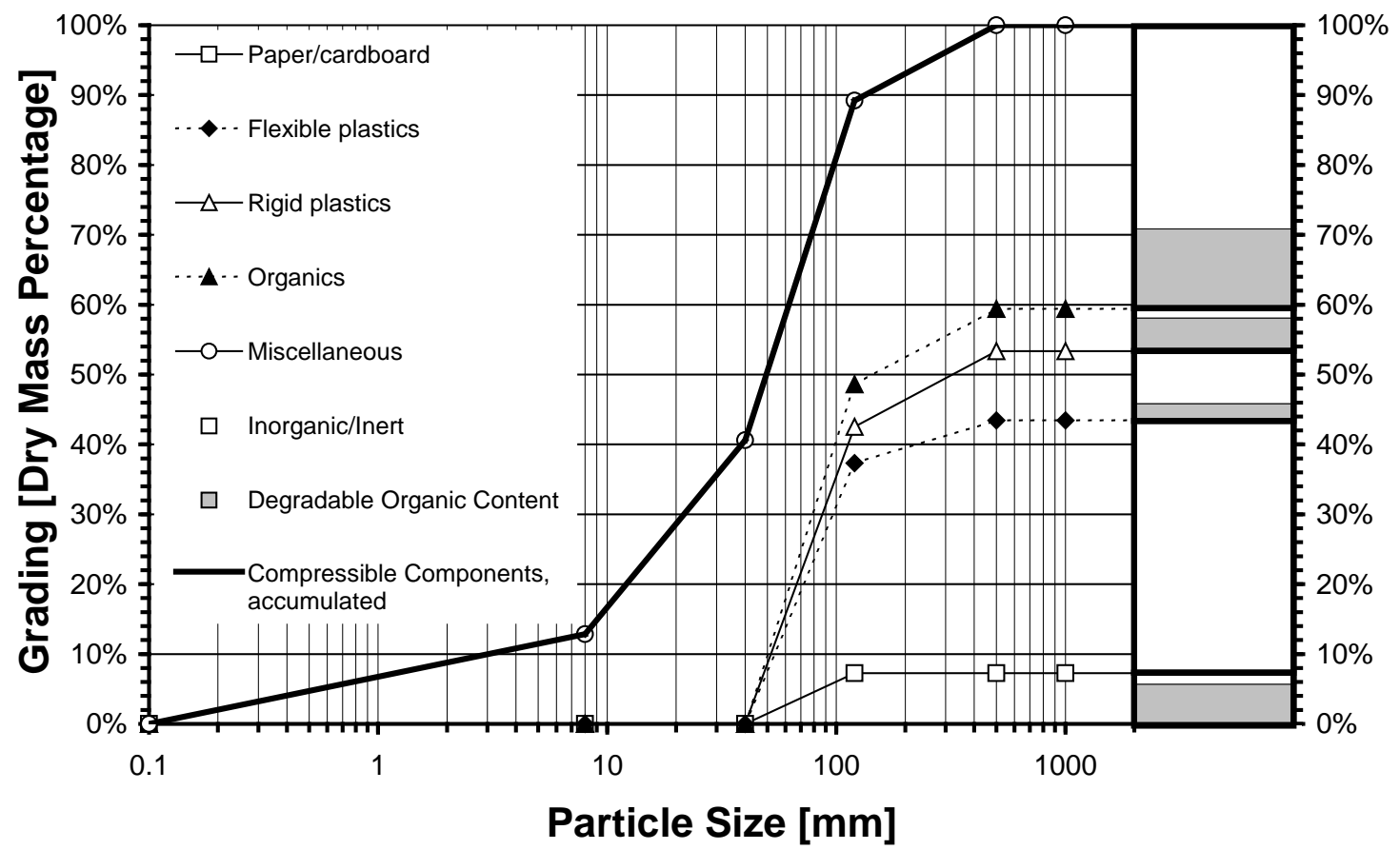

Fig. 13: Compressible components: Material groups, gradings, organic content of the material groups related to $100 \%$ of the overall sample mass (data from Kölsch, 1996; data for miscellaneous material modified by the Authors) 


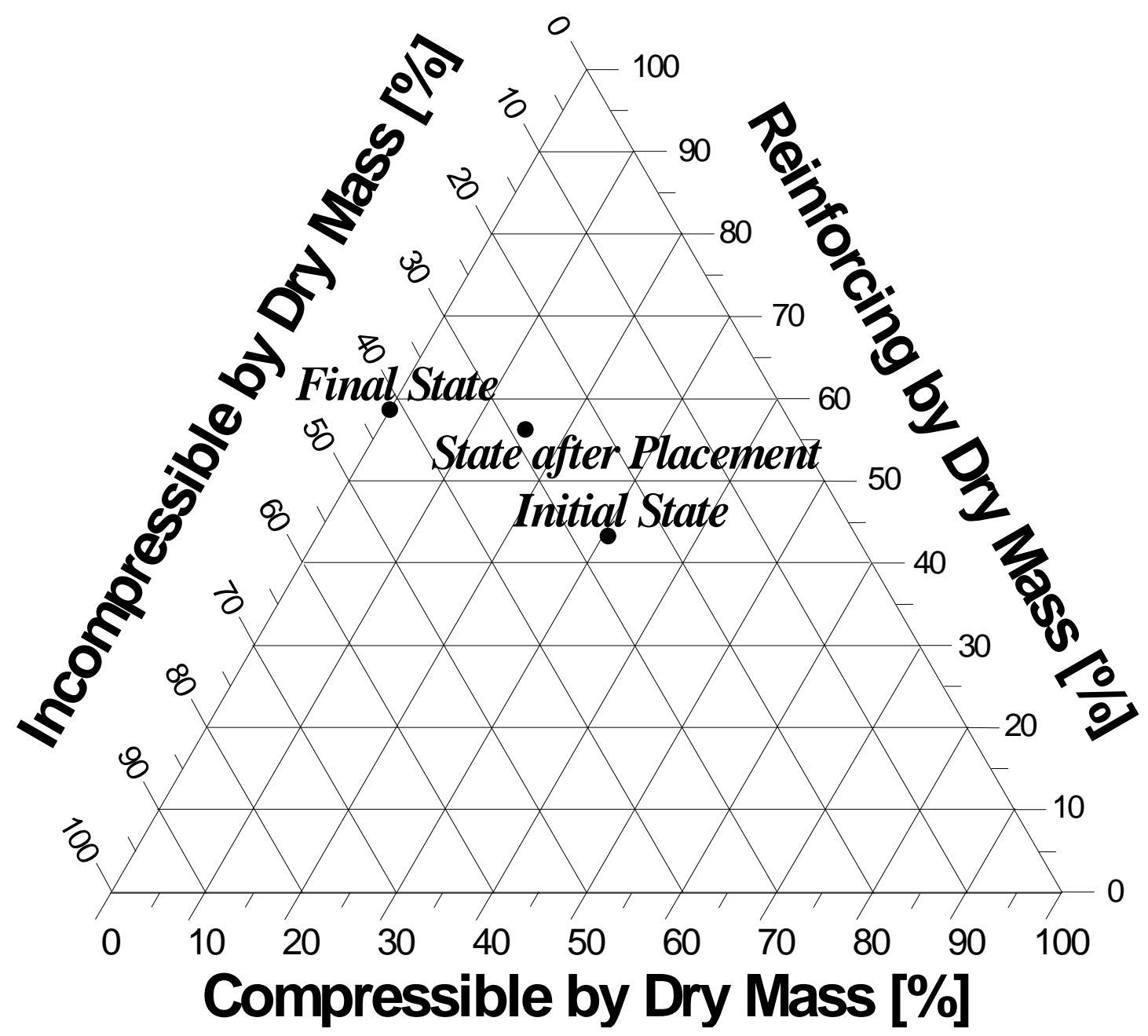

Fig. 14: Demonstration of the potential use of shape-related classification to aid evaluation of changes in mechanical behaviour of MSW bodies resulting from placement and final state after long-term degradation. 